\title{
What-You-Look-For-Is-What-You-Find - The consequences of underlying accident models in eight accident investigation manuals
}

\author{
Jonas Lundberg, C. Rollenhagen and Erik Hollnagel
}

\section{Linköping University Post Print}

N.B.: When citing this work, cite the original article.

Original Publication:

Jonas Lundberg, C. Rollenhagen and Erik Hollnagel, What-You-Look-For-Is-What-You-Find - The consequences of underlying accident models in eight accident investigation manuals, 2009, Safety Science, (47), 10, 1297-1311.

http://dx.doi.org/10.1016/j.ssci.2009.01.004

Copyright: Elsevier http://www.elsevier.com/

Postprint available at: Linköping University Electronic Press http://urn.kb.se/resolve?urn=urn:nbn:se:liu:diva-21192 


\section{What you look for is what you find - The consequences of underlying accident models in eight accident investigation manuals \\ Jonas Lundberg $^{1}$ Carl Rollenhagen $^{2}$ Erik Hollnagel $^{3}$}

${ }^{1}$ Jonas Lundberg (Corresponding author)

Linköpings Universitet

Department of Science and Technology, ITN

Campus Norrköping

SE - 60174 Norrköping

Sweden

Jonas.lundberg@itn.liu.se

Phone: +4611363452

${ }^{2}$ Carl Rollenhagen

Royal Institute of Technolology

Department of Philosophy and History of Technology

SE - 10044 Stockholm

Sweden

${ }^{3}$ Erik Hollnagel ${ }^{1}$

Department of Computer and Information Science

Linköpings Universitet

SE - 58183 Linköping

Sweden

1 Present affiliation: MINES ParisTech, Crisis and Risk Research Centre, Sophia Antipolis, France 


\begin{abstract}
Accident investigation manuals are influential documents on various levels in a safety management system, and it is therefore important to appraise them in the light of what we currently know - or assume - about the nature of accidents. Investigation manuals necessarily embody or represent an accident model, i.e., a set of assumptions about how accidents happen and what the important factors are. In this paper we examine three aspects of accident investigation as described in a number of investigation manuals. Firstly, we focus on accident models and in particular the assumptions about how different factors interact to cause - or prevent - accidents, i.e., the accident "mechanisms." Secondly, we focus on the scope in the sense of the factors (or factor domains) that are considered in the models - for instance (hu)man, technology, and organisation (MTO). Thirdly, we focus on the system of investigation or the activities that together constitute an accident investigation project/process. We found that the manuals all used complex linear models. The factors considered were in general (hu)man, technology, organization, and information. The causes found during an investigation reflect the assumptions of the accident model, following the 'What You Look For Is What You Find' or WYLFIWYF principle. The identified causes typically became specific problems to be fixed during an implementation of solutions. This follows what can be called 'What You Find Is What You Fix' or WYFIWYF principle.
\end{abstract}

Keywords: Accident investigation, accident models 


\section{What you look for is what you find - The consequences of underlying accident models in eight accident investigation manuals}

\section{Introduction}

Accident investigation practices always make some assumptions about how accidents happen and what one should do to prevent them. In one of the few studies conducted on accident models in investigating agencies, (Benner, 1985) evaluated the merits of 17 US investigation methodologies, and found considerable differences in their effectiveness. Benner listed ten criteria as desirable for accident models, namely that they should be: realistic, definitive, satisfying, comprehensive, disciplining, consistent, direct, functional, non-casual, and visible. He also listed ten criteria for accident investigation methodologies, namely encouragement, independence, initiatives, discovery, competence, standards, enforcement, states, accuracy, and closed-loop. Of the 17 methodologies investigated, the events process model and the events analysis process (Benner, 1975) scored highest as an accident model or an accident investigation method, respectively.

Accident models and thinking about accidents have changed over time. The basic accident models and investigation techniques in the 1920s (Bureau of Labor Statistics, 1920) intended to deal with lost-time accidents in factories, associated with events such as operators loosing their thumbs in mechanical saws (i.e, an occupational safety focus). Today, more sophisticated accident models are needed to deal with events in complex systems such as railroads and nuclear power plants. Perrow (1999) described how accidents in complex and tightly coupled systems differ from accidents in linear and loosely coupled system. Accidents in complex and tightly coupled systems should furthermore be seen as normal rather than abnormal occurrences. The accidents that were the focus of early accident investigations work have certainly not disappeared, but new kinds of accidents have emerged. In response to these changes, the scientific community has proposed new accident models and new investigation methods.

Investigation manuals can be said to embody or represent accident models, i.e., a set of assumptions about how accidents happen and what the important factors are. They reflect, for example, aspects of an investigation that an organization may find important, and imply how accidents are assumed to occur and how they can best be prevented in the future. The manuals can be normative, be meant for beginners, be a set of rules for all investigators, or simply be a source of inspiration that investigators can draw upon. With their multiple functions, accident manuals are usually important constituents of safety management systems. They define an implicit (and sometimes explicit) norm ("work as imagined") for what a satisfactory investigation is, even though they do not necessarily reflect what goes on in actual investigations ("work as done"). Investigation manuals are influential documents on various levels in a safety management system, and it is therefore important to appraise them in the light of what we currently know - or assume - about the nature of accidents.

In this paper we examine three aspects of accident investigation as described in a number of investigation manuals. Firstly, we focus on accident models and in particular assumptions about how different factors interact to cause - or prevent accidents, i.e., the accident "mechanisms." Secondly, we focus on the scope in the 
Lundberg, J., et al. What-You-Look-For-Is-What-You-Find - The consequences of underlying accident models. Safety Sci. (2009), doi:10.1016/j.ssci.2009.01.004

sense of the factors (or domains) that are considered in the models - for instance (hu)man, technology, and organization (MTO). Thirdly, we focus on the system of investigation or the activities that together constitute an accident investigation. That includes both interactions during the investigation and activities that draw upon the results of the investigation. Following that, we assess a selection of investigation manuals in terms of accident models, scope, and system of investigation.

\section{Accident models}

The two aspects, accident models and scope, are often described together and have historically often changed in parallel. However, it is important to separate the two since the outcome of an analysis in practice will depend not only on the view on causality (i.e., views about the accident "mechanism"), but also on what kinds of factors are included as causes and contributing factors. Following the proposal of Hollnagel (2004), accident models can be considered as belong to one of three major categories.

An accident investigation always follows a method or a procedure. There are many different methods available, both between and within domains, that may differ with respect to how well formulated and how well founded they are. The method will direct the investigation to look at certain things and not at others. It is simply not possible to begin an investigation with a completely open mind, just as it is not possible passively to 'see' what is there. Accident investigations can therefore be characterised as conforming to the What-You-Look-For-Is-What-You-Find (WYLFIWYF) principle (Hollnagel, 2008). Since the main purpose of an accident investigation is to find ways in which to avoid future occurrences, and since people rarely heed the advice to look for 'second stories' (Woods \& Cook, 2002), the corollary to the WYLFIWYF principle becomes the What-You-Find-Is-What-YouFix (WYFIWYF) principle, which means that the causes found during an investigation are seen as specific, individual problems to be fixed during implementation.

\subsection{Simple linear system models (cause-effect models)}

Early models focused on preventing accidents in comparatively simple systems consisting of an operator working with a machine, illustrated by the following quote:

"Case 3 - In splitting a board, a circular-saw operator suffered the loss of his thumb when, in violation of instructions, he pushed the board past the saw with his fingers, instead of using the push stick that had been provided for the purpose. He stated that he had always done such work in this manner and had never before been hurt. He had performed similar operations on an average of twenty times a day for three months and had therefore exposed his hand in this way over one thousand five hundred times" (Heinrich 1931, p 94).

For these situations, Heinrich (1931) proposed that the most proximate cause should be prevented, following a recommendation from the US department of Labor (1920) That same definition suggested that more distant causes should be pursued for severe accidents, such as train accidents. Thus, the model proposed by Heinrich is linear, considering only the immediate surroundings, including line management. Although commitment from higher management levels were seen as vital for success in implementing safety work, Heinrich did not think it was a fruitful approach to point to higher management levels as causes. It is noteworthy that two lines of enquiry were 
Lundberg, J., et al. What-You-Look-For-Is-What-You-Find - The consequences of underlying accident models. Safety Sci. (2009), doi:10.1016/j.ssci.2009.01.004

considered: The first went through the person or surroundings, looking for causes to actions that in hindsight seemed incorrect, or for causes of problems with equipment or other items in the surroundings. The second line of enquiry went towards the line manager, looking for reasons why the accident was not prevented.

\subsection{Complex linear system models (epidemiological models)}

When considering accidents in the home and in the military, Gordon (1949) discovered that environment factors seemed to combine with the initiating event so that the resulting accident was out of proportion to the event. To characterize such accident, an "epidemiological approach" was proposed. Causes were seen as originating from a host (e.g., foot discipline), an agent (e.g., faulty ladder, cold), and the environment (e.g., terrain, management of troops). The analysis would start out with the agent, followed with the mechanism of how the agent came into play, and then an analysis of the cause.

"The causative factors in accidents have been seen to reside in agent, in the host, and in the environment. The mechanism of accident production is the process by which the three components interact to produce a result, the accident: it is not the cause of the accident." (op. cit., p. 509)

Turner (1978) considered severe accidents or disasters, such as the Glamorgan mine accident of 1965 where an underground explosion killed 31 men and seriously injured one. In Turner's view, the incubation period was a distinguishing factor between disasters and less severe accidents. That echoes the view of the epidemiological approach of Gordon (1949) that the accident can be out of proportion to the precipitating event. Turner focused on the subset of the (set of) chains of events that are discrepant, forming before the onset of a disaster. It was importance to Turner's view that this subset was unnoticed before the disaster stroke, since that contributed to the surprise of the event. He defined the incubation period as "the accumulation of an unnoticed set of events which are at odds with the accepted beliefs about hazards and the norms for their avoidance." (Turner, $1978 \mathrm{p} \mathrm{85)}$ ). Turner's view thus incorporated both the perspective of the 1920s that preceding events should be considered for more severe accidents, and the view of the 1940s of the epidemiology of causes. It did not contradict the view of Heinrich (1931) that for some accidents there might be few unnoticed discrepant casual chains, meaning that the precipitating event was important. However, Turner showed that for severe accidents, the situation could be the opposite. With many unnoticed discrepant casual chains the precipitating event is of minor importance. Turner highlighted communication and cultural factors as important in the accidents analyzed in the 1978 work. Today, the complex linear accident model is best known as the Swiss Cheese model (Reason, 1997).

\subsection{Complex interactions}

Considering complex systems, such as nuclear power plants, Perrow (1999) discussed the inevitability of disasters, in what he called 'Normal Accidents.' Perrow focused on two system properties, called coupling and interaction.

- Coupling referred to whether control was direct or indirect. Direct control, corresponding to tight coupling, is for instance to open a valve by pushing a button. Indirect control, corresponding to loose coupling, is for instance to tell someone else to open the valve, in which case that person may opt to do that, or instead carry out some other act that is deemed more appropriate or urgent. An advantage of loose coupling is that poor decisions or incidents do not 
Lundberg, J., et al. What-You-Look-For-Is-What-You-Find - The consequences of underlying accident models. Safety Sci. (2009), doi:10.1016/j.ssci.2009.01.004

necessarily propagate through the system, whereas a disadvantage is that correct control decisions may not propagate either. In tightly coupled systems, delays in processing are not possible, sequences of operations are invariant, there is little slack (in supplies, equipment, staff), buffers and redundancies are designed-in, and there is limited substitutability.

- Interactions referred to the degree of conspicuity or obviousness of the system. In a system with linear interactions, events at one point will have predictable effects further down the line. In a system with complex interactions, components are tightly spaced and in close proximity, there are many common-mode connections and interconnected subsystems, events at one point may have effects upstream through feedback loop, and may also spread as through a causal net, with many effects emerging at the same time and at different places. Interaction and coupling affect each other so that, for instance, a linear system that is loosely coupled becomes less predictable than if it is tightly coupled (Perrow, 1999).

Discussing accidents such as the Chernobyl nuclear disaster, Reason (1997) focused on the discrepant casual chains where managerial activities at the "blunt end" could lead to latent conditions at the "sharp end". Reason spoke of the precipitating event as the active failure and discussed the role of different levels of management, such as management of the organisation and regulating authorities. The notion of the sharp end is, of course, relative. For instance, when a cause has been located at a management level, this situation can be viewed as a sharp end event with latent conditions formed at a more remote blunt end. The corresponding safety strategy is defence-in-depth, focusing on barriers to prevent further accidents. Yet the barriers themselves are prone to fail, as described by the well-known Swiss cheese model.

\subsection{Performance variability (Resilience)}

In many systems where the environment and the system itself change, attempts to constrain the functions are futile and unexpected events are inevitable. In such systems, the variability of performance is not only a threat, but also a necessity since the intractability of the system makes it impossible to prescribe actions in complete detail. The variability of normal performance may, however, from time to time combine in unanticipated ways, leading to unexpected events. To avoid negative effects of such unexpected events the focus must not only be on maintaining an equilibrium or steady state, but also on transitions between states and the creation of new stable states in recovering from an instability (Sundström \& Hollnagel, 2006).

In order to account for what happens in complex systems, resilience engineering makes three important assumptions that differ from a more traditional view of safety and accidents.

- Performance conditions are always underspecified. Since it is impossible to specify work in every detail, individuals and organizations must always adjust their performance to match the current conditions. Since resources and time are finite, such adjustments will inevitably be approximate. Performance variability is unavoidable, but is a source of success as well as of failure.

- Many adverse events can be attributed to a breakdown or malfunctioning of components and normal system functions, but many cannot. Such intractable events are best understood as the result of unexpected combinations of normal performance variability. Adverse events are therefore seen as representing the converse of the adaptations necessary to cope with real-world complexity. 
- Effective safety management cannot be based on hindsight, nor rely on error tabulation and the calculation of failure probabilities. Safety management must not only be reactive, but also proactive. Resilience Engineering looks for ways to enhance the ability of organizations to create processes that are robust yet flexible, to monitor and revise risk models, and to use resources proactively in the face of disruptions or ongoing production and economic pressures.

While Resilience Engineering as such is a relatively young phenomenon, many of the ideas can be traced 20-30 years back in time. Resilience requires an organization that at all times is (Hollnagel, in print):

- responsive, in the sense that it is able to respond effectively when something happens,

- attentive, in the sense that it knows what to look for in the current situation and that it regularly updates its knowledge, competence and resources,

- anticipatory, in the sense that it prepares for what might conceivably happen in the future in both the short and the long term, and

- able to learn from past experience, i.e., from past investigations. This, of course, presupposes that the investigations have been properly performed.

The application of Resilience Engineering requires the ability to analyze, measure and monitor the resilience of organizations in their operating environment, tools and methods to improve an organization's resilience vis-à-vis the environment, and finally techniques to model and predict the short- and long-term effects of change and decisions on risk. It is a consequence of this perspective that the primary target for safety management should be to increase the organization's ability on all levels to adjust its functioning in the face of changes and disturbances, rather than to reduce risks and negative events by constraining performance through more rigidly defined activities (Hollnagel, Woods, \& Leveson, 2006).

\section{Scope}

Whereas early work (e.g. Heinrich, 1931) focused on management control of workers to increase safety in factories, later accidents such as the Three Mile Island and the Challenger accidents have changed the focus. Attention has turned from line managers and sharp-end operators, towards management and regulatory agencies at the blunt end of operations. The focus is not only on organization of operation, but also on conditions for operations such as economy, and less well-defined notions such as safety culture and safety climate. Whereas early research pointed at management as being responsible for $90 \%$ of all industrial accidents (Heinrich, 1928) there are many different kinds of components and relations to consider. The list below describes various factors and generic questions usually found important by authors in the safety community and among practitioners, but it is by no means complete. In the following sections we use the first letters to refer to the factors in short form, e.g. MTOI for (hu)man, technology, organization, information.

- Social: What are the values in the organization? How well do people know each other? Do they trust each other? Are there unofficial ways of getting things done? What is the social background of the people involved in accidents?

- Technological: How well does the technology work? 
Lundberg, J., et al. What-You-Look-For-Is-What-You-Find - The consequences of underlying accident models. Safety Sci. (2009), doi:10.1016/j.ssci.2009.01.004

- Organizational: Hierarchies of control within the organization. Including regulating agencies within the organization and outside the organization. Activities are such as incident reporting systems, safety audit organizations, and maintenance.

- Human (Man): The outcome of actions by people can be analyzed, in terms of whether successes were due to correct or incorrect actions, with regards to how adequate rules and regulations were. To the extent that the concept of an incorrect action is part of the analysis, these actions can be classified in various ways, such as to their cognitive type.

- Safety culture: how shall safety culture be defined and assessed?

- Information: It is also vital to understand why actions seemed reasonable at the time. What information was available? How far was there between people, through the formal organizational hierarchy? What made people think that they were safe, when they were in fact unsafe?

- Economy vs. production is often seen as a central issue for the understanding of accidents in recent publications, particularly the balance between production and safety goals.

Within each of these broad categories, there are many very specific areas of expertise. This means that the competences of the team or investigators and of specialists available as a resource becomes critical for the quality of the result.

The scope and the accident model are often described together in the literature. For instance, Heinrich (1959) listed three factors as causes of accidents, namely social factors (e.g., inheritance, environment), faults of people (e.g., violent temper, ignorance of safe practice), and unsafe acts (standing under suspended loads). These three factors were in this early model the first part of a five stage linear model, fittingly depicted as a line of dominoes. If any of the three initial factors would be removed by management that would prevent the two last factors, the accident and injury from happening. In that model, technical faults were also seen as caused by faults of people, and as appearing at the same stage as unsafe acts in the line of dominoes. Thus, the linear sequence was not primarily a sequence of events, but a sequence of factors that in turn caused an accident. (Heinrich did, however, not believe that the fall of the first domino piece would inevitably cause the fall of the final domino piece, unlike how a real row of dominoes works. The analogy was merely that removal of one domino piece in between would hinder the row from falling further). Moreover, as illustrated by a hand lifting a domino brick, in the 1959 illustration, a second line of enquiry went from the unsafe act or condition, through the line manager to high management focusing on two factors, namely control and commitment to safety.

More recent models mix factors and events, such as Reason's (1997) model of organizational accidents. In Reason's model, organizational accidents were seen as occurring due to several events that coincide. Each event trajectory was seen as a line of four factors. The two first factors were organizational factors (e.g., planning, auditing, budget) and local workplace factors (error-provoking conditions such as undue time pressure) whereas the third factor, the unsafe act (including faults of people), remained from Heinrich's model. The fourth factor was the failed defenses or barriers. However, rather than focusing on one event (one trajectory) as the only cause of an accident, Reason viewed an accident as a combination of event trajectories, each ending with a failed defense. In the resulting model, widely known as the Swiss 
cheese model, an organization's defenses against failure are represented as a series of barriers, like slices of Swiss cheese. The holes in the cheese slices represent weaknesses in individual parts of the system, and continually vary in size and position in all slices. The system as a whole produces failures when all of the holes in each of the slices momentarily align, permitting "a trajectory of accident opportunity", so that a hazard passes through all of the holes in all of the defenses, leading to a failure.

Finally, contemporary models, such as the functional resonance accident model or FRAM (Hollnagel, 2004) do not focus on event trajectories. Instead, they focus on functions and performance conditions for the functions. The system is described in terms of the functions required to accomplish its purpose, and the conditions are what may affect the variability of each function. Functions are described in terms of six aspects, namely input, output, time, control, preconditions, and resources. Every function is coupled to one or more other functions through its output, which for other functions may constitute the input or any of the other aspects - output excepted, of course. It is recognised that the performance of a function may vary, and that variability depends on the performance conditions as well as the outputs from other functions. Examples of performance conditions are quality of communication, training and experience, etc.. Sometimes the performance may be better than usual, and sometimes worse. In this model, accidents occur due to functional resonance, when the variability of output of several functions coincide so that performance of the system as a whole exceeds safe limits.

In summary, Heinrich's domino model consists of a linear propagation of cause-effect links, corresponding to an event chain. Reason's model Swiss cheese consists of a linear combination of active failures and latent conditions, corresponding to several event chains. Hollnagel's functional resonance model consists of interdependent functions whose performance depends both on other functions (through the six aspects of each function) and on different factors (performance conditions). Thus, the role of factors (such as (hu)man, technology, organization), will differ between the models, and each model will provide a different result depending on the factors considered.

The description of an accident is a description of something that has happened, hence provides the reality that the investigation must deal with. Accident investigation methods, however, do not always focus on the same features or facets of this reality. One model may consider factor $\mathrm{X}$ as the most important, while another may highlight factor Y. While there is no objectively true description of an accident, we soon learn from experience which factors are important and which are not. And we also find that some methods, because of the nature of their underlying model, may miss factors that others deem important. This may happen because the method was developed for different circumstances. The domino model, for instance, was developed to meet the problems of industrial safety in the 1930s. It consequently focuses on factors that were important then (because they are built into the model, so to speak), but may on the other hand miss factors that are important now. A more recent example of this is the attempt to develop an extended version of Tripod, to account for extraorganisational factors (van Schaardenburgh-Verhoeve, Corver \& Groeneweg, 2007).

\section{Investigation activities and system}

Although investigation activities are often intertwined, they do have different ends, and they are given different amount of resources, such as time and personnel. The 
amount of time resources spent on different activities affect what scope and what accident models can practically be employed. This set of accident investigation activities (below) represents rather typical stages and activities that most investigators encounter in one or the other form.

1. Initiation of an investigation. In this stage a decision is take to initiate an investigation. Various criteria can be used to assess if an event should proceed to a deeper investigation.

2. Planning: In this stage the specific investigation project is planned regarding time and personnel resources. Often encountered sub activities in this stage are to find persons for interviews, going through documents of relevance for the investigation, etc.

3. Data collection: Various sources are utilized to find data of relevance for the event; such data can consists of, for example: observations, interviews, studies of documents, experimentation etc.

4. Representation; related to the data collection is various means to represent data in a form suitable for the investigation. Common forms of representation are event trees, logical trees, ordering of events in a time sequence, representation of barriers in diagrams etc.

5. Analysis of the accident/incident: At the core of an investigation is analysis of how various causes/conditions etc. are connected. This reconstruction (which is a better word than "analysis" in this context) is greatly influenced by various experiences and beliefs about how accidents are supposed to happen. Depending on explicit or implicit accident model used, the results may vary great what "factors" that are considered relevant for the investigation.

6. Recommendations; at this stage a set of remedial actions are produced. This is one of the most important steps in an accident investigation and is usually depicted as a set of "recommendations" in an accident report.

7. Documentation/writing the report: A report is usually produced that documents the result of the investigation and which contains a set of recommendations. In context of this report a review is usually made so that significant actors may express their opinions about the report.

8. Decisions about actions and implementation of remedial actions.

9. Follow up activities

Many interesting questions can be asked in relation to the various steps taken in an accident investigation. Since the investigation is a process one may, for example, ask how the transition is made between different stages or activities. One important transition, for example, is the passage from problem identification (problem finding) to problem solving i.e. when actual solutions to identified problems should be constructed/adopted. This corresponds roughly to the transition between step 5 and step 6 above. The analysis itself is influenced, or biased, by the underlying accident model, as argued throughout this paper. The recommendations are also influenced by something, although this is more likely to be political and economical considerations, local traditions, expediency, etc. The recommendations may therefore be affected by other things than the outcome of the accident analysis, which in the worst case only has a minor impact.

Moreover, the activities are conducted in a system of investigation practices. That consists not only of the flow between activities, but also of a flow between actors 
Lundberg, J., et al. What-You-Look-For-Is-What-You-Find - The consequences of underlying accident models. Safety Sci. (2009), doi:10.1016/j.ssci.2009.01.004

within the investigation process, and with actors outside of it. Those actors are for instance involved in higher-level safety work summarizing the big picture of many investigations, or they are rescue workers acting in the same area as the investigation, or other external actors such as the police or other authorities.

\section{Method}

We contacted eight organizations with accident investigation activities, and requested their accident investigation manuals (Table 1). The Swedish Maritime Inspectorate investigates accidents involving marine traffic, and Swedish Civil Aviation Authority investigates aviation accidents. The Swedish Work Environment Authority investigates accidents at work places, and is therefore not limited to any specific domain. The Swedish Rail Administration investigates accidents in the railway system, and the Swedish Road Administration investigates accidents in the road traffic system. The Swedish Association of Local Authorities and Regions investigates accidents in medical care. Statoil Hydro is a major oil company. Forsmark FKA operates nuclear power plants. These eight organisations were selected to cover a broad range of domains each with a clear accident investigation tradition.

\begin{tabular}{|ll|}
\hline Translation to English & Swedish name and industrial domain \\
\hline The Swedish Maritime Inspectorate & Sjöfartsinskpektionen (maritime safety) \\
Swedish Work Environment Authority & Arbetsmiljöverket (occupational safety) \\
Swedish Rail Administration & Banverket (railroad safety) \\
Swedish Road Administration & Vägverket (road safety) \\
& \\
Swedish Civil Aviation Authority & Luftfartsstyrelsen (aviation safety) \\
$\begin{array}{l}\text { Swedish Association of Local Authorities and } \\
\text { Regions }\end{array}$ & Sveriges Kommuner och Landsting (former \\
Statoil Hydro & Landtingsförbundet) (patient safety) \\
Forsmark, FKA & Former Norsk Hydro (offshore safety) \\
\hline
\end{tabular}

Table 1. Organizations, translations of Swedish names.

A qualitative analysis of eight investigation manuals (Table 2) was conducted. The materials were firstly analyzed by the first author of this paper using the broad categories outlined above (accident model and scope, activities, and system). The categories were derived from the literature review in sections two to four of this paper. The analysis was conducted in several steps. As expected, the manuals as a rule did not describe the accident models they were based on or how the methods were derived from, and justified by, the model. Further analysis steps were therefore required to infer the accident models from descriptions of the method and from descriptions of investigation objectives (e.g., to find a root cause). The analysis of accident models was thus not limited to cause-analysis activities, but covered all activities that were described in the manuals. 
Lundberg, J., et al. What-You-Look-For-Is-What-You-Find - The consequences of underlying accident models. Safety Sci. (2009), doi:10.1016/j.ssci.2009.01.004

\begin{tabular}{|lllll|}
\hline no & Manual & Words & Pages & Year \\
\hline 1 & Forsmarks kraftgrupp (manual with report template) & $9 \mathrm{k}$ & 37 & 2005 \\
2 & $\begin{array}{l}\text { Sveriges Kommuner och Landsting (including risk } \\
\text { analysis) }\end{array}$ & $16 \mathrm{k}$ & 64 & 2005 \\
3 & Norsk Hydro (manual) & $2 \mathrm{k}$ & 10 & 2005 \\
4 & Banverket (manual and report template) & $13 \mathrm{k}$ & 44,18 & 2003,2002 \\
\hline 5 & Sjöfartsinspektionen (decisions, process, routine) & $3 \mathrm{k}$ & $7,4,5$ & $2000,2005,2005$ \\
6 & Arbetsmiljöverket & $6 \mathrm{k}$ & 37 & 2004 \\
7 & Vägverket (manual, report template, checklists) & $3 \mathrm{k}$ & 17,10, & 2005 \\
\hline 8 & Luftfartsstyrelsen (manual) & $17 \mathrm{k}$ & 35 & 2001 \\
\hline
\end{tabular}

Table 2. Materials analyzed

As the manuals were analysed, the initial set of categories was adjusted to reflect the contents of the manuals. More detailed categories were taken in use for aspects that were covered in depth in the manuals than for aspects that had less coverage. This meant that the analysis of the last manual was done with a larger set of categories and more detail in the classification. The whole analysis was therefore revised to ensure that the same analysis categories were applied to all manuals. The results are summarized in the next section, which describes the contents of each manual. To help with the descriptions, software was used to recall the contents marked with each analysis category so that the contents of the manuals could be reviewed when writing the analysis. Tables 4 and 5 were also prepared during this step. Finally, the comparison (section 7) was made, based on the tables and the textual summaries in section 6 .

\section{Description of manuals}

The results are first described for all manuals, describing each manual in terms of accident model and scope, activities, and overarching system. These issues sometimes overlap, such as regarding responsibilities and roles for specific activities, and are then described only under one of the headings. In section 7, the findings are summarized and the manuals are compared.

\subsection{Forsmarks kraftgrupp}

The Forsmark manual mainly focused on activities, but also defined a system for investigation practices. The manual also proposed a company culture that encourages initiatives for starting investigations.

\subsubsection{Accident models and scope}

The Forsmark manual had an explicit scope including (hu)man, technology and organization (MTO). The document did not emphasize information as an MTO category in its explicit scope, although information is one aspect that was later listed as relevant for analysis, and which apparently was given the same weight as the other aspects.

The accident model involved epidemiology of latent failures combined with active failures during the accident event. The analysis of latent failures included factors at the blunt end such as the safety programs, and the management of the safety programs that should prevent negative events. For instance, the manual suggested analysis of 
Lundberg, J., et al. What-You-Look-For-Is-What-You-Find - The consequences of underlying accident models. Safety Sci. (2009), doi:10.1016/j.ssci.2009.01.004

latent failures such as why known problems have not been remedied. The manual also focused on system stability, with a focus on barriers.

\subsubsection{Activities}

In the planning stage, the Forsmark manual covered how to initiate an investigation, focusing on responsibilities for initiating and allocating resources. The manual described two levels of investigation.

Planning focused on responsibilities for initiating investigation, allocating resources and other prerequisites for investigations. For data collection, the document recommended analysis of previous reports, in addition to current data. There was a checklist for data to collect and an instruction for conducting interviews. As usual, there was no clear-cut division between analysis and representation. The document had extensive instructions of how to model diagrams for the analysis. Also, there were definitions, examples, instructions, checklists and rules of thumb for analysis and modeling. There was a focus on event sequences and blunt end causes, in particular barriers, including consequences of failure of additional barriers. For recommendations, the document provided rules of thumb, and checklists to explore alternatives. There was no further method support for exploring alternatives, except the instruction to go back in the chain of events, and to consider MTOI aspects. There were instructions on evaluating the recommendations found, for instance with regard to whether they increase or decrease complexity, mentioning the importance of partwhole relations. There were also recommendations to hold a meeting with stakeholders to decide what recommendations to include. There was moreover a report outline with examples. The system description covered what to do with the report when it has been produced, and how do deal with conflicts in finalizing it. For implementation, there was an instruction on how to document the decision by management of what recommendations to implement. Follow-up was only briefly covered as a method step, but is covered in more detail in the system description.

\subsubsection{System}

The Forsmark manual described how to set up an investigation system, focusing on a working group for MTO issues. It described what competences to include in the team, and from what organizational units they should be recruited. It also covered how to maintain and improve team competence. The system description furthermore made recommendations about how many meetings to hold, and how to propagate investigation results through the organization. The manual covered the dealings between the MTO group and other organization entities, such as the security group. The manual also briefly covered circulation of investigation results outside the own organization.

\subsection{Sveriges Kommuner och Landsting (Swedish Association of Local Authorities and Regions)}

On the policy level, the manual described the need for education of personnel, and success-factors, such as support by management. These factors can also be seen as encouraging a safety culture.

The focus of the manual was on investigation activities rather than on the system of investigation.

\subsubsection{Accident models and scope}

The Landstinget manual had an explicit MTO perspective. Information was not 
Lundberg, J., et al. What-You-Look-For-Is-What-You-Find - The consequences of underlying accident models. Safety Sci. (2009), doi:10.1016/j.ssci.2009.01.004

explicitly mentioned as a category. However, also in this manual, information was seen as an important analysis category in the advice given for practice. There was also an explicit strive to improve safety culture. However, one perspective standing in contrast to improved safety culture that was referred to, but not further emphasized, was the better, safer, cheaper perspective. The manual prescribed that the economic consequences of the suggested remedial actions should be considered.

Epidemiology of latent conditions, both at the sharp end the accident as in poorly designed equipment, and further away from the accident scene at the blunt end, such as in organizational factors was emphasized in the manual. The manual also focused on system stability through barriers. These aims were backed up in the analysis process description, by analysis and representation activities.

\subsubsection{Activities}

Regarding planning, the Landstinget manual described roles responsible for initiating the investigation, and provided rules of thumb and examples, including a decision matrix, for deciding what kind of investigation to start, depending on the seriousness of the incident (based on the consequences of the incident, and the likelihood of it happening again). Moreover, the team roles were described for the investigation, with responsibilities and competence needed. The document provided rules of thumb for team size, and time needed for an investigation. For data collection, the manual made recommendations and checklists of what data to collect, and it provided instructions for conducting interviews with an example. Analysis was supported by instructions and examples of representing the incident in diagrams as a chain of negative events, with underlying blunt-end causes for each event, and failed barriers / defenses in the chain of events. The manual assumed that failure of people would be at the end of the chain, caused by the circumstances under investigation. Modeling was also supported by instructions for going about the analysis work from event chain analysis, to barrier analysis, building the model in a series of steps. Furthermore, checklists and examples supported analysis. As a final step in the analysis process, the manual instructed and exemplified how to make recommendations connecting them to the causes in the model. The instructions supported finding a set of recommendations and evaluating them. Alternatives were considered by going from the sharp end to the blunt end, evaluating the value of different kinds of barriers. A checklist for evaluating whether the recommendations would be effective also supported the recommendations step. The manual also provided instructions and a template for documentation. The manual moreover provided a brief overview of how to conduct further improvement work needed when implementing the recommendations. There was an emphasis on testing the recommendations on a smaller scale before implementing them at large. The manual also covered follow-up, defining roles and activities for experience feedback and for checking what happened to the recommendations.

\subsubsection{System}

That results were to be fed back into the organization for learning purposes was emphasized in the Landstinget manual. There were many references to reference channels, such as regulations. Quality feedback was however limited to an estimate by the work leader about the time taken for analysis work, and whether that had been sufficient.

The manual focused on the investigation process, and the roles of commissioning body team leader, analysis leader, and responsible for documentation. The commissioning body was responsible for feedback of results into the organization. 
Lundberg, J., et al. What-You-Look-For-Is-What-You-Find - The consequences of underlying accident models. Safety Sci. (2009), doi:10.1016/j.ssci.2009.01.004

The manual did not define any over-arching group or system, although the manual aims at authorities in the organization." There were few instructions regarding circulation of documents outside of the organization.

\subsection{Norsk Hydro (Statoil Hydro)}

The Norsk Hydro manual defined processes for investigations of different kinds, divided into three levels, depending on their potential and actual outcome, as judged before the investigation. All stages were briefly described, with instructions on what actions to carry out. There were references to checklists and modeling techniques described elsewhere, but the manual itself had no examples, no modeling technique descriptions and few checklists. An investigation system was defined, focusing on relations to other authorities during data collection, and for severe accidents, the manual prescribed an analysis of the system for investigations.

\subsubsection{Accident models and scope}

The review system for severe accidents had an explicit MTO perspective. The Norsk Hydro manual also included information as a category in its practical advice.

The accident model included epidemiology of latent and active failures and the sharp and blunt end. That included the analysis of barriers, focusing on increased stability of the system. For actual or potential accidents of catastrophic proportions the manual recommended that the system for experience feedback should be reviewed, but no practical data collection of other advice regarding that was given.

\subsubsection{Activities}

Three processes were defined in the Norsk Hydro manual, for three levels of accident and incident severity. The process was firstly supported by definitions of key terms. The planning stage focused on what level of investigation to implement, what competences and other resources to allocate, and on securing data. A matrix was included to support the decision. To secure data was also focused in the data collection stage, which was further supported by a checklist of what data to collect. The focus was on the scene of the accident. The manual itself did not cover representation, but references were made to an appendix, regarding recommended representation techniques. There was also a report template. Analysis focused on what to factors to analyze. There was a focus on barriers, event sequence, and hidden dependencies. Regarding recommendations, there were instructions that recommendations for remedial actions should be made. For implementation and follow-up instructions were given on whom the responsible parties are, and timing for the most severe level of accidents and incidents. For implementation, there was an instruction to make action plan and assign a responsible for the plan. For follow-up, responsible parties were described, along with timing, progress reporting, and a corporate audit group for severe accidents.

\subsubsection{System}

Regarding the system for investigations, the Norsk Hydro documents provided instructions for appointing investigation teams, including their roles, what competences and representatives to include. The document furthermore instructed that procedures for relating to media and authorities should be established. Relations with other authorities were also emphasized in the data collection stage, to ensure that data would not be disturbed without good reasons (not only for the investigation but also for authorities such as the police). To manage the quality and impact of investigations, 
Lundberg, J., et al. What-You-Look-For-Is-What-You-Find - The consequences of underlying accident models. Safety Sci. (2009), doi:10.1016/j.ssci.2009.01.004

the manual described that a corporate audit group should evaluate the implementation of recommendations made after severe accidents. The manual was less clear regarding the follow up of less severe accidents and incidents.

\subsection{Banverket (Swedish Rail Administration)}

The Banverket manual primarily and extensively instructed on the planning stage, on what activities to perform, on roles for the activities, and on coordination between investigation activities, rescue activities, and external actors. The rescue effort was included in the analysis. The manual had a particular emphasis on preserving data for collection, through co-ordination with other activities. The manual was complemented by a report template, which made extensive usage of checklists. The manual did not describe diagramming techniques, and did not have method support on how to achieve recommendations from data.

\subsubsection{Accident models and scope}

In the cause-analysis described in the Banverket manual, information was not mentioned as a category, but was covered just like the MTO aspects. There was an emphasis on economy when initiating investigations, giving more resources to accidents with more severe economic consequences. However, the focus on economy was restricted to the consequences of the accident, and was not in focus in the cause analysis.

There was a focus on epidemiology of causes in the sharp end, with causes traced back to the blunt end of the organization, focusing on management. To improve safety, there was a focus on increased stability, in the report template. It included barrier analysis, although the method was not described in the manual.

\subsubsection{Activities}

Two processes were defined in the Banverket manual, for severe class one events, and for less severe class two events. The planning stage focused on how to initiate an investigation, on roles, collaborations with other investigators, resources and constraints, in particular on time constraints. There were also instructions for planning investigations based on several events. The primary focus of the manual was on planning, and on describing the system (see below). The data collection stage focused on roles, interactions with others, and ensuring that evidence is left undisturbed until the investigation has looked into it. The report template had an extensive checklist of data to include. The analysis stage focused on direct and underlying causes with a focus on management. Analysis of the rescue effort was included. The report template also included barrier analysis. The manual had few instructions regarding details on how to carry out the analyses. Although there were brief instructions on how to describe the events and the scene of the accident and a report template, there were no more advanced representation techniques. The manual did not emphasize the process of making recommendations, apart from stating that there should be a connection to causes, and that loose formulations should be avoided. There was however instructions on documenting what recommendations are implemented. Decisions, actions, and a time plan were to be included. There was an instruction to integrate follow up with normal safety management, and instructions to form a central analysis group.

\subsubsection{System}

The Banverket manual primarily focused on the system for investigation. It had 
Lundberg, J., et al. What-You-Look-For-Is-What-You-Find - The consequences of underlying accident models. Safety Sci. (2009), doi:10.1016/j.ssci.2009.01.004

extensive coverage on coordinating accident investigation activities with activities of other actors, such as the police. It both covered how to co-ordinate investigation activities with other accident investigation agencies such as Arbetsmiljöverket (the Swedish Work Environment Authority) and Elsäkerhetsverket (the Swedish National Electrical Safety Board), as well as sharing the results of the investigation. It also covered co-ordination with overarching rescue and restoration activities. In particular, the manual emphasized coordination issues regarding the preservation of data to collect. Moreover, the manual had extensive coverage of defining roles, and their responsibilities, competences, and how to appoint the different roles. Integrity was emphasized as more important than gains from collaboration with others. There were frequent references to other documents, used as reference channels. There was also a feedback form in the manual, for managing improvements of the process.

\subsection{Sjöfartsinspektionen (The Swedish Maritime Inspectorate)}

MTO aspects were briefly mentioned in the manual, but there was insufficient material to make any statement regarding scope.

The manual focused on the overarching system for investigation practices. They provided few details regarding investigation work, and thus there was no ground for analyzing perspectives on investigation work. The documents were quite brief compared to some of the other manuals, and thus also covered less details.

\subsubsection{Activities}

The Sjöfartsinspektionen manual primarily focused on the system of investigation, rather than on describing activities. For planning, the manual described roles and responsibilities for initiation, internal and external. There were instructions to collect data. There were checklists regarding what analyses to make, but they were on a high level of abstraction. There was a focus on event sequences and causes. For recommendations, the manual prescribed a review round with affected parties before official distribution. Regarding generation of alternatives, the manual merely described that recommendations should be made. For follow-up, the manual recommended a review by audit group. It also defined who is responsible for followup and provided instructions for dissemination.

\subsubsection{System}

The Sjöfartsinspektionen manual mainly focused on roles and in particular interactions with the Swedish Accident Investigation Board. Interactions with other parties, such as the police were also covered, and with actors who risk being be blamed (they were to be given the opportunity to read and comment on the report). The manual also prescribed a higher-level system of safety work, emphasizing the larger picture emerging from negative events. Also, the manual emphasized distribution of recommendations. There were frequent references to other documents, used as reference channels.

\subsection{Arbetsmiljöverket (Swedish Work Environment Authority)}

The Arbetsmiljöverket manual was divided into two parts. The first part described the work as a process, whereas the other part provided two examples of how analyses can be carried out. The process was described with focus on roles, responsibilities, competence, resources, and interactions with other processes such as legal investigations. 
Lundberg, J., et al. What-You-Look-For-Is-What-You-Find - The consequences of underlying accident models. Safety Sci. (2009), doi:10.1016/j.ssci.2009.01.004

\subsubsection{Accident models and scope}

The Arbetsmiljöverket manual had an MTO perspective, and also included for instance instructions, an information aspect. One of the methods described included safety culture and control mechanisms for accident prevention. The manual also emphasized the ethical aspect of not assigning blame to individuals.

The manual modeled the epidemiology of latent conditions, such as deviations from normal circumstances, with event chains from the sharp end to management at the blunt end. There was also an analysis of how stability has been lost through missing or breached barriers.

\subsubsection{Activities}

The Arbetsmiljöverket manual described roles and responsibilities for initiating an investigation, in the planning stage, with a focus on the responsibilities of organizations to report negative events. There was also an instruction emphasizing the need for allocating the necessary competences for the investigation. Regarding data collection, the manual was very brief, focusing on interactions with other organizations, such as the police, and preserving evidence. Overarching categories of data to collect were presented, and there was a report template with checklists. The manual presented two examples of analysis processes. The examples focused on the analysis stage of the investigation, providing modeling techniques, examples of models of an event, and also some checklist questions to guide the analysis. The first analysis method example described analysis based on a sharp end - blunt end causality model, from resource loss, to event (e.g., physical contact, time pressure), to direct causes (missing barrier, misuse of equipment), to underlying causes (e.g., individual factors, work organization), to management (e.g., routines, rules). The second analysis example described how to model event chains, underlying factors, deeper analysis of underlying factors, barriers, and deviations from normal circumstances. The description of analysis thus focused on event sequences, latent conditions, blunt end, safety culture, and barriers. The manual provided a report template with a checklist for contents and distribution, as well as roles responsible for archiving reports and notifications of negative events. None of the analysis processes provided guidance on how to proceed from the analysis to recommendations. There was an instruction to archive the report.

\subsubsection{System}

The Arbetsmiljöverket manual had a basis in regulations, used as a reference channel in the manual motivating instructions. The manual mainly defined a system for initiating, carrying out investigations, and distributing reports. There was also a focus on archives for investigations and reported negative events, and on distribution (including external actors). The manual in particular instructed on interactions with the police and the Swedish Prosecution Authority There was moreover a focus on the employer, on what the employer is responsible for, and what can be asked of the employer.

\subsection{Vägverket (Swedish Road Administration)}

The manual described studies of individual accidents, and as well as deep studies of accidents, and defined an overarching system focusing on quality and improvement of investigation work. The manual provided templates for investigation reports, which at the same time served as checklists. Analysis was not focused in the manual - there were detailed advice on what data to collect, and from whom to obtain it, but no 
Lundberg, J., et al. What-You-Look-For-Is-What-You-Find - The consequences of underlying accident models. Safety Sci. (2009), doi:10.1016/j.ssci.2009.01.004

modeling techniques were provided for analysis. There manual described two kinds of recommendations, quick recommendations from what becomes obvious by just visiting the scene of the accident, and recommendations based on the analysis.

\subsubsection{Accident models and scope}

The Vägverket manual had an MTO perspective, with a focus on (hu)man, in particular when rules intentionally have been breached, and on technology (inadequate technology such as lack of safety belt), and in other cases on organization, on the failure of the system to protect the people in it. For follow-up, the manual presented some safety culture issues, such as information campaigns in schools.

The manual furthermore focused on the chain of events at the sharp end. Moreover, in the deep studies, the manual aimed at improving anticipation, to consider different possible scenarios. The follow-up stage also presented activities aimed at improving safety at the blunt end.

\subsubsection{Activities}

The Vägverket manual described, in the planning phase, how to initiate an investigation, emphasizing the need for having the right competences in the team. This was supported by a checklist for competences. Responsibilities of people in other organizations to initiate organizations was also described. Data collection was supported by a checklist, which emphasized obtaining data from other actors. There were also detailed checklists in the report templates, supporting the data collection and analysis work. These checklists were the primary representation tools proposed in the manual. The description on how to conduct analysis focused on overarching goals, rather than detailed instructions on how to carry out the analysis. Regarding recommendations, the manual was equally brief, exemplifying what kinds of recommendations were expected. The manual defined two kinds of recommendations, firstly recommendations that immediately become evident after visiting the scene of the accident, and secondly recommendations based on the analysis. There was no advice regarding how to create alternative (divergent) recommendations based on the analysis apart from the generation of recommendations based on sharp end factors, and no advice for converging on fewer solutions. In addition to the documentation templates for the report, there were also instructions for entering information about accidents in databases. Regarding follow-up and implementation the manual focused on collaboration with other actors, such as information in schools (a safety culture issue), or municipalities, for instance posing demands on safety belts in bus traffic (a blunt-end management issue). Archiving in databases to follow-up on trends was recommended. Regarding implementation of deep study recommendations, there were also examples of sharp end factors, such as removing dangerous objects near the road (e.g., large stones).

\subsubsection{System}

The Vägverket manual defined a system for exchanging experience and develop their way of working. The manual defined two roles for co-ordination, on the national and regional levels, and also the role of investigator, with a list of responsibilities for each role.

\subsection{Luftfartsstyrelsen (Swedish Civil Aviation Authority)}

The manual did not describe analysis methods, but contained references to other 
Lundberg, J., et al. What-You-Look-For-Is-What-You-Find - The consequences of underlying accident models. Safety Sci. (2009), doi:10.1016/j.ssci.2009.01.004

documents. The manual instead focused on roles and responsibilities for activities, and on what kinds of data to collect.

\subsubsection{Accident models and scope}

The manual had an MTOI scope in the instructions for what data to collect. The data (the manual) was insufficient to analyze the accident model.

The manual primarily focused on the system of investigation, and instructed on roles for various actors, on assigning responsibilities, and on coordination of responsibilities. Regarding the process, the manual focused on data collection. The informal diagrams illustrated the system used by Luftfartsstyrelsen to work with investigations, and focused on relations to Swedish Accident Investigation board, and to segelflygförbundet (Swedish Soaring Federation). The manual emphasized that blame should not be sought, and emphasized the need for independence of the investigation.

\subsubsection{Activities}

The Luftfartsstyrelsen manual described roles and responsibilities for each stage. In the description of the planning stage there were checklists for items to contain in an accident notification. There were also instructions and checklists on what data to collect, for instance flight recorder data and autopsy information. The manual also contained instructions for protecting data from being disturbed before it has been collected. Interactions between actors were described well. The manual moreover contained a report template, which also had checklists of what data to report. The report system screen shots also contained fields for specific data, which could function as a checklist. Regarding recommendations, there were instructions that recommendations for remedial actions should be made. Follow up was covered as a demand for feedback about the actions or lack of actions taken. Roles and responsibilities for sharing information were described. The manual prescribed documentation on what had and had not been done.

\subsubsection{System}

The manual provided a system description of roles and responsibilities for different stakeholders, and the interactions between them. There was both a focus on appointing personnel for the investigation, and on review and dissemination of the report. That was provided in the informal Luftfartsstyrelsen diagrams, which described the more specific way of working for Luftfartsstyrelsen. The manual explicitly excluded appointment of blame in its recommendations. There were also explicit statements emphasizing integrity. Whereas the ICAO manual also regulated distribution of the report, including interviews and other investigation materials, the Swedish addition to the manual allowed distribution. The manual also recommended an incident reporting system, something, which was also described in the 2003/42/EG directive.

\section{Comparison of manuals}

The manuals are below compared with respect to accident models and scope, activities, and system, showing the main points that they have in common and in what respects they differ. For Sjöfartsinspektionen and Luftfartsinspektionen, the data was insufficient to analyze the accident model and scope. 
Lundberg, J., et al. What-You-Look-For-Is-What-You-Find - The consequences of underlying accident models. Safety Sci. (2009), doi:10.1016/j.ssci.2009.01.004

\subsection{Accident models and scope}

In a majority of the studied manuals, the accident models adopted have been clearly influenced by complex linear system models (epidemiological models) in which accidents are described as a consequence of latent failures (weaknesses) in combination with active failures. Concepts such as barriers, latent weaknesses, bluntend, sharp-end are frequently mentioned (or implied in other terms) in the context of these models.

In Table 3 below, some basic concepts associated with the accident model characteristics of the manuals are summarized. For two of the seven manuals (Sjöfartsinspektionen and Luftfartsinspektionen), data was insufficient for the analysis. The first column regards the accident model, and the second column regards scope.

\begin{tabular}{|c|c|c|}
\hline & $\begin{array}{l}\text { Concept used or implied supporting } \\
\text { accident model characteristics }\end{array}$ & Scope \\
\hline Forsmark & $\begin{array}{l}\text { barriers, } \\
\text { safety system, } \\
\text { safety system management }\end{array}$ & MTOI \\
\hline Landstinget & $\begin{array}{l}\text { sharp end, } \\
\text { blunt end } \\
\text { barriers }\end{array}$ & $\begin{array}{l}\text { MTOI, } \\
\text { safety culture, } \\
\text { "better, safer, cheaper", } \\
\text { economy of remedial actions }\end{array}$ \\
\hline Norsk Hydro & $\begin{array}{l}\text { sharp end, } \\
\text { blunt end, } \\
\text { barriers, } \\
\text { investigation system (severe accidents) }\end{array}$ & MTOI \\
\hline Banverket & $\begin{array}{l}\text { barriers, } \\
\text { blunt end (management) }\end{array}$ & MTOI \\
\hline Arbetsmiljö-verket & $\begin{array}{l}\text { barriers, } \\
\text { sharp end, blunt end (management) }\end{array}$ & $\begin{array}{l}\text { MTOI, } \\
\text { safety culture }\end{array}$ \\
\hline Vägverket & $\begin{array}{l}\text { sharp end } \\
\text { blunt end (remedial actions in deep studies) }\end{array}$ & $\begin{array}{l}\text { MTO } \\
\text { safety culture (deep studies) } \\
\text { anticipation (deep studies) }\end{array}$ \\
\hline
\end{tabular}

Table 3. Characteristics of accident models. Sjöfartsinspektionen and Luftfartsinspektionen are excluded due to lack of data (see below). 
The main points of similarity between the manuals (Table 3) were that most of them included sharp end causes, in particular barriers, as well as blunt end causes. The scope was in most cases (hu)man, technology, organization and information (MTOI), and in half of the cases also safety culture. In sum, as we see in Table 3, the accident model characteristics that were covered were sharp end versus blunt end (5), safety system (1), safety system management (1), barriers (5), investigation system (1). The scope was (hu)man, technology, organization (6), information (5), safety culture (3), anticipation (1), economy (1).

\subsection{Activities}

In Table 4 (below) the focus of the description of activities in the manuals are summarized. Some items described in the table seem similar. They may be more or less specific, such as focus on management being a specific blunt end factor. The respective section on each manual clarifies what is meant by each item.

The manuals emphasized the stages from planning to analysis. In sum, as we see in Table 4, regarding the activities described for the initiation and planning stages, many manuals focused on roles and responsibilities for initiation as well as allocation of resources. Some manuals also described different levels of investigation. For the data collection stage, most manuals provided checklists for data collection, or overarching categories of items to collect. Many manuals also focused on interactions with other organizations. Regarding representation, all manuals but one had a report template, and several manuals provided instructions inside the template. Many, but not all, manuals also had instructions for how to make visual representations of accident events. The main foci of analysis were event sequences, sharp end causes, in particular regarding barriers, and blunt end causes, including a focus on management. One manual also included safety culture, but otherwise the manuals were rather similar with regards to analysis.

Turning to recommendations and follow-up the manuals in general contained fewer details. Apart from general issues, the recommendations step can be divided into the substeps of creating alternatives and evaluating them. Several manuals stayed on the general level with a non-committal statement that recommendations should be made. The remaining manuals provided little detail regarding how to create alternatives. In one case there was the advice to go consider the causes from the blunt end to the sharp end or to categorise the remedial actions into MTOI categories. Turning to evaluation of recommendations, some manuals recommended meetings with affected parties. The use of checklists was also described in few manuals, but in general there was little emphasis on the evaluation of alternatives. The same was the case for the follow-up. Several manuals suggested the use of some kind of central group (e.g., central analysis group, audit group) or recommended the activity of follow up on trends. 


\begin{tabular}{|c|c|c|c|c|c|c|c|}
\hline Manual & Planning and initiation & Data collection & Representation & Analysis & Recommendations & $\begin{array}{l}\text { Adjustment and } \\
\text { implementation }\end{array}$ & Follow-up \\
\hline $\begin{array}{l}\text { Forsmarks } \\
\text { kraftgrupp }\end{array}$ & $\begin{array}{l}\text { Decide between two } \\
\text { levels of investigation. } \\
\text { Focus on responsibilities } \\
\text { for initiating investigation } \\
\text { and allocating resources. } \\
\text { Prerequisites for } \\
\text { investigations. }\end{array}$ & $\begin{array}{l}\text { Analysis of previous } \\
\text { reports, in addition to } \\
\text { current data. A checklist } \\
\text { for data to collect. } \\
\text { Instruction for conducting } \\
\text { interviews. }\end{array}$ & $\begin{array}{l}\text { Instructions of how } \\
\text { to model diagrams } \\
\text { for the analysis. } \\
\text { Report template with } \\
\text { examples. } \\
\text { Definitions, } \\
\text { examples, } \\
\text { instructions, } \\
\text { checklists and rules } \\
\text { of thumb for analysis } \\
\text { and modelling. }\end{array}$ & $\begin{array}{l}\text { Event sequence } \\
\text { and blunt end } \\
\text { causes. Barriers. } \\
\text { Consequences of } \\
\text { failure of } \\
\text { additional } \\
\text { barriers. }\end{array}$ & $\begin{array}{l}\text { Rules of thumb, and } \\
\text { checklists. } \\
\text { Alternatives: chain of } \\
\text { events, checklist: } \\
\text { MTO+I aspects. } \\
\text { Evaluation: checklist, } \\
\text { stakeholder meeting. } \\
\text { Part-whole, } \\
\text { measurability. }\end{array}$ & $\begin{array}{l}\text { Instruction on how to } \\
\text { document the decision } \\
\text { by management } \\
\text { regarding what } \\
\text { recommendations to } \\
\text { implement. }\end{array}$ & MTO group. \\
\hline Landstinget & $\begin{array}{l}\text { Responsible for initiating } \\
\text { the investigation, } \\
\text { Rules of thumb, decision } \\
\text { matrix, and examples for } \\
\text { investigation type } \\
\text { Team roles: } \\
\text { responsibilities, } \\
\text { competence } \\
\text { Rule of thumb for team } \\
\text { size, and time. }\end{array}$ & $\begin{array}{l}\text { Recommendations / } \\
\text { checklist of what data to } \\
\text { collect, instructions for } \\
\text { conducting interviews } \\
\text { with an example. }\end{array}$ & $\begin{array}{l}\text { Instructions of how } \\
\text { to model diagrams } \\
\text { for the analysis. } \\
\text { Report template }\end{array}$ & $\begin{array}{l}\text { Checklists, } \\
\text { examples, } \\
\text { techniques. } \\
\text { Event sequence } \\
\text { and blunt end } \\
\text { causes. Barriers }\end{array}$ & $\begin{array}{l}\text { Instructions, } \\
\text { examples, } \\
\text { connection to the } \\
\text { causes in the model. } \\
\text { Alternatives: } \\
\text { Barriers, going from } \\
\text { sharp to blunt end } \\
\text { Evaluation: checklist } \\
\text { for approximation of } \\
\text { effectiveness }\end{array}$ & $\begin{array}{l}\text { Emphasis on testing } \\
\text { and improving the } \\
\text { recommendations on a } \\
\text { smaller scale before } \\
\text { implementing them at } \\
\text { large } \\
\text { Roles responsibilities, } \\
\text { and time for } \\
\text { implementation }\end{array}$ & $\begin{array}{l}\text { Roles and } \\
\text { activities for } \\
\text { experience } \\
\text { feedback, } \\
\text { checking } \\
\text { recommendatio } \\
\text { ns }\end{array}$ \\
\hline Norsk Hydro & $\begin{array}{l}\text { Deciding which of three } \\
\text { levels of investigation to } \\
\text { initiate. Decision matrix. } \\
\text { What competences and } \\
\text { other resources to } \\
\text { allocate. } \\
\text { Securing data. }\end{array}$ & $\begin{array}{l}\text { Preserving data. } \\
\text { Interactions with other } \\
\text { authorities. } \\
\text { Data collection checklist. } \\
\text { Focus on accident scene. }\end{array}$ & $\begin{array}{l}\text { References are } \\
\text { made to an } \\
\text { appendix, regarding } \\
\text { recommended } \\
\text { representation } \\
\text { techniques. } \\
\text { Instructions for } \\
\text { report. }\end{array}$ & $\begin{array}{l}\text { Checklist for what } \\
\text { to analyze. Focus } \\
\text { on barriers, event } \\
\text { sequence, and } \\
\text { hidden } \\
\text { dependencies }\end{array}$ & $\begin{array}{l}\text { Alternatives: } \\
\text { Instruction that } \\
\text { recommendations } \\
\text { for remedial actions } \\
\text { should be made. } \\
\text { Focus on limiting } \\
\text { recurrence and } \\
\text { consequences of } \\
\text { accidents and } \\
\text { incidents. }\end{array}$ & $\begin{array}{l}\text { Instruction to make } \\
\text { action plan. } \\
\text { Responsible for the } \\
\text { plan. }\end{array}$ & $\begin{array}{l}\text { Responsible } \\
\text { parties. Timing: } \\
\text { Progress } \\
\text { reporting. } \\
\text { Severe } \\
\text { accidents: } \\
\text { corporate audit } \\
\text { group }\end{array}$ \\
\hline Banverket & $\begin{array}{l}\text { Decide which of two } \\
\text { levels of investigation, or } \\
\text { multi-event investigation } \\
\text { to initiate. } \\
\text { Roles, resources and } \\
\text { constraints, e.g., time } \\
\text { constraints and } \\
\text { competences. } \\
\text { Collaborations with other } \\
\text { investigators. } \\
\text { Re-opening of } \\
\text { investigations. }\end{array}$ & $\begin{array}{l}\text { Roles. Interactions with } \\
\text { other authorities. } \\
\text { Preserving data. } \\
\text { Data collection checklist } \\
\text { in report template. } \\
\text { Including analysis of the } \\
\text { rescue effort. }\end{array}$ & $\begin{array}{l}\text { Brief instructions on } \\
\text { how to describe the } \\
\text { events and the } \\
\text { scene of the } \\
\text { accident. Report } \\
\text { template. }\end{array}$ & $\begin{array}{l}\text { Direct and blunt } \\
\text { end causes. } \\
\text { Focus on } \\
\text { management and } \\
\text { barriers. }\end{array}$ & $\begin{array}{l}\text { Alternatives: } \\
\text { Connections to } \\
\text { causes. } \\
\text { Evaluation: } \\
\text { Avoid loose } \\
\text { formulations. } \\
\text { Connections to } \\
\text { causes. }\end{array}$ & $\begin{array}{l}\text { Documentation of } \\
\text { decisions and actions. } \\
\text { Time plan. }\end{array}$ & $\begin{array}{l}\text { Central analysis } \\
\text { group. } \\
\text { Instruction to } \\
\text { integrate follow } \\
\text { up with normal } \\
\text { safety } \\
\text { management. }\end{array}$ \\
\hline $\begin{array}{l}\text { Sjöfarts- } \\
\text { inspektionen }\end{array}$ & $\begin{array}{l}\text { Roles and responsibilities } \\
\text { for initiation, internal and } \\
\text { external. } \\
\text { Role descriptions }\end{array}$ & $\begin{array}{l}\text { slnstruction to collect data. } \\
\text { Law support for acquiring } \\
\text { data. }\end{array}$ & $\begin{array}{l}\text { Report template. } \\
\text { High-level checklists }\end{array}$ & $\begin{array}{l}\text { Event sequence, } \\
\text { causes. }\end{array}$ & $\begin{array}{l}\text { Instruction that } \\
\text { recommendations } \\
\text { for remedial actions } \\
\text { should be made. } \\
\text { Evaluation: Review } \\
\text { round with affected } \\
\text { parties. }\end{array}$ & - & $\begin{array}{l}\text { Review by audit } \\
\text { group. } \\
\text { Responsible for } \\
\text { follow-up. } \\
\text { Instructions for } \\
\text { dissemination. }\end{array}$ \\
\hline $\begin{array}{l}\text { Arbetsmiljö- } \\
\text { inspektionen }\end{array}$ & $\begin{array}{l}\text { Roles and responsibilities } \\
\text { in other organizations for } \\
\text { initiation. } \\
\text { Incident reporting of } \\
\text { damaged organizations. } \\
\text { Allocating competences }\end{array}$ & $\begin{array}{l}\text { slnteractions with other } \\
\text { organizations. } \\
\text { Preserving data. } \\
\text { Overarching categories } \\
\text { of data to collect. }\end{array}$ & $\begin{array}{l}\text { Two modelling } \\
\text { schemes. } \\
\text { Report template with } \\
\text { checklist. }\end{array}$ & $\begin{array}{l}\text { Event sequence, } \\
\text { latent conditions, } \\
\text { blunt end, safety } \\
\text { culture. Barriers. }\end{array}$ & $\begin{array}{l}\text { Instruction that } \\
\text { recommendations } \\
\text { for remedial actions } \\
\text { should be made. }\end{array}$ & - & Archiving \\
\hline Vägverket & $\begin{array}{l}\text { Roles and responsibilities } \\
\text { in other organizations for } \\
\text { initiation. } \\
\text { Checklist for } \\
\text { competences }\end{array}$ & $\begin{array}{l}\text { sCheklists: } \\
\text { Data, in report templates. } \\
\text { Other actors to collect } \\
\text { data from / interactions } \\
\text { with other actors. }\end{array}$ & $\begin{array}{l}\text { Detailed checklists in } \\
\text { report templates. }\end{array}$ & $\begin{array}{l}\text { Classification } \\
\text { scheme. }\end{array}$ & $\begin{array}{l}\text { Immediate (obvious) } \\
\text { recommendations, } \\
\text { Analysis-based } \\
\text { recommendations. } \\
\text { Alternatives: focus } \\
\text { on sharp end } \\
\text { factors. }\end{array}$ & $\begin{array}{l}\text { Examples of remedial } \\
\text { actions that have been } \\
\text { previously made. }\end{array}$ & $\begin{array}{l}\text { Archiving in } \\
\text { databases. } \\
\text { Follow-up on } \\
\text { trends. Use by } \\
\text { other parties. }\end{array}$ \\
\hline $\begin{array}{l}\text { Luftfarts- } \\
\text { styrelsen }\end{array}$ & $\begin{array}{l}\text { Roles and responsibilities } \\
\text { for each stage } \\
\text { Checklist for items to } \\
\text { contain in accident } \\
\text { notification. }\end{array}$ & $\begin{array}{l}\text { sRoles and responsibilities } \\
\text { for preserving and } \\
\text { providing data. } \\
\text { Interactions between } \\
\text { actors. } \\
\text { Checklists }\end{array}$ & $\begin{array}{l}\text { Report template with } \\
\text { checklist. }\end{array}$ & $\begin{array}{l}\text { Instruction to } \\
\text { report systemic } \\
\text { and immediate } \\
\text { causes. }\end{array}$ & $\begin{array}{l}\text { Instruction that } \\
\text { recommendations } \\
\text { for remedial actions } \\
\text { should be made. }\end{array}$ & - & $\begin{array}{l}\text { Roles and } \\
\text { responsibilities: } \\
\text { sharing } \\
\text { information. } \\
\text { Documentation } \\
\text { on what has } \\
\text { been done, and } \\
\text { not. }\end{array}$ \\
\hline
\end{tabular}

Table 4. Summary of accident investigation activities

23 Article in press. Page numbers and formatting does not reflect print formatting and numbering. 
Lundberg, J., et al. What-You-Look-For-Is-What-You-Find - The consequences of underlying accident models. Safety Sci. (2009), doi:10.1016/j.ssci.2009.01.004

\subsection{System}

The manuals had different foci in their system descriptions, as summarized in Table 5. The themes described were, communication and collaboration with other agencies during investigation, roles and responsibilities, dissemination of results, overarching safety work and organizational learning.

\begin{tabular}{|c|c|c|c|c|}
\hline & $\begin{array}{l}\text { Communication and } \\
\text { collaboration }\end{array}$ & $\begin{array}{l}\text { Roles and } \\
\text { responsibilities }\end{array}$ & $\begin{array}{l}\text { Dissemination } \\
\text { of results }\end{array}$ & $\begin{array}{l}\text { Safety work and } \\
\text { organizational } \\
\text { learning }\end{array}$ \\
\hline Forsmark & $\begin{array}{l}\text { with other groups in the } \\
\text { own organisation }\end{array}$ & $\begin{array}{l}\text { MTO group, } \\
\text { competences, } \\
\text { representatives }\end{array}$ & $\begin{array}{l}\text { within and } \\
\text { outside the } \\
\text { organisation }\end{array}$ & $\begin{array}{l}\text { focus on team } \\
\text { competence }\end{array}$ \\
\hline Landstinget & - & $\begin{array}{l}\text { Roles for } \\
\text { investigation and } \\
\text { dissemination }\end{array}$ & $\begin{array}{l}\text { within the } \\
\text { organisation }\end{array}$ & $\begin{array}{l}\text { focus on internal } \\
\text { dissemination of } \\
\text { reports for learning }\end{array}$ \\
\hline Norsk Hydro & $\begin{array}{l}\text { with media, } \\
\text { with authorities during } \\
\text { data collection }\end{array}$ & $\begin{array}{l}\text { Roles, } \\
\text { competences, } \\
\text { representatives }\end{array}$ & & corporate audit group \\
\hline Banverket & $\begin{array}{l}\text { with authorities } \\
\text { investigation agencies, } \\
\text { rescue services }\end{array}$ & $\begin{array}{l}\text { Roles, } \\
\text { responsibilities, } \\
\text { competences }\end{array}$ & $\begin{array}{l}\text { sharing results } \\
\text { with other } \\
\text { agencies }\end{array}$ & feedback form \\
\hline $\begin{array}{l}\text { Sjöfarts- } \\
\text { inspektionen }\end{array}$ & $\begin{array}{l}\text { Authorities, } \\
\text { Actors who might feel } \\
\text { blamed by the } \\
\text { investigation, } \\
\text { the Swedish Accident } \\
\text { Investigation Board }\end{array}$ & $\begin{array}{l}\text { Roles and } \\
\text { responsibilities for } \\
\text { initiating an } \\
\text { investigation }\end{array}$ & Emphasized & $\begin{array}{l}\text { A group analyzing } \\
\text { the bigger picture }\end{array}$ \\
\hline $\begin{array}{l}\text { Arbetsmiljö- } \\
\text { verket }\end{array}$ & $\begin{array}{l}\text { Responsibilities of the } \\
\text { employer, } \\
\text { Interactions with } \\
\text { authorities (police, } \\
\text { prosecutor) }\end{array}$ & $\begin{array}{l}\text { Roles and } \\
\text { responsibilities for } \\
\text { initiating an } \\
\text { investigation }\end{array}$ & $\begin{array}{l}\text { Archiving of the } \\
\text { report }\end{array}$ & - \\
\hline Vägverket & $\begin{array}{l}\text { Interactions with other } \\
\text { institutions, such as } \\
\text { schools, municipalities, } \\
\text { for overarching safety } \\
\text { work }\end{array}$ & $\begin{array}{l}\text { Roles and } \\
\text { responsibilities for } \\
\text { initiating an } \\
\text { investigation, } \\
\text { competences }\end{array}$ & $\begin{array}{l}\text { Archiving of the } \\
\text { report }\end{array}$ & $\begin{array}{l}\text { same as } \\
\text { communication and } \\
\text { collaboration }\end{array}$ \\
\hline $\begin{array}{l}\text { Luftfarts- } \\
\text { styrelsen }\end{array}$ & $\begin{array}{l}\text { Interactions between } \\
\text { stakeholders for all } \\
\text { stages of the } \\
\text { investigation and } \\
\text { dissemination }\end{array}$ & $\begin{array}{l}\text { Roles, } \\
\text { responsibilities, for } \\
\text { all stages of the } \\
\text { investigation }\end{array}$ & $\begin{array}{l}\text { Regulations for } \\
\text { distribution, roles } \\
\text { and } \\
\text { responsibilities }\end{array}$ & $\begin{array}{l}\text { Recommendation to } \\
\text { implement incident } \\
\text { reporting. }\end{array}$ \\
\hline
\end{tabular}

Table 5. Summary of Investigation system

There were some issues that can also be described as properties of the investigation system at large, in addition to how they manifest themselves in different investigation steps. As we see in Table 5, the instructions for Communication and Collaboration were quite diverse, with authorities as a common factor for three manuals. The items were: with other groups in the own organization (1), with media, with authorities during data collection (1), with authorities (3), investigation agencies (1), rescue services (1), actors who might feel blamed by the investigation (1), the Swedish Accident Investigation Board (1), responsibilities of the employer (1), interactions with other institutions, such as schools, municipalities, for overarching safety work (1), interactions between stakeholders for all stages of the investigation and 
Lundberg, J., et al. What-You-Look-For-Is-What-You-Find - The consequences of underlying accident models. Safety Sci. (2009), doi:10.1016/j.ssci.2009.01.004

\section{dissemination (1).}

The manuals also described roles and responsibilities, although some of them focused on initiating an investigation. The items were (Table 5): MTO group (1), roles (3), competences (4), responsibilities (2), representatives (2), roles for investigation and dissemination (1), roles and responsibilities for initiating an investigation (3).

Regarding dissemination of the report, there were different foci, both on where to distribute, and on regulations for distribution. The items were (Table 5): within the organization (2), outside the organization (2), archiving (1), regulations for distribution (1).

Concerning safety work and organizational learning, there were also different foci. The items were (Table 5): focus on team competence (1), internal dissemination of reports for learning (1), corporate audit group (1), a group analyzing the bigger picture(1), feedback form (1), recommendation to implement incident reporting(1), interactions with other institutions, such as schools, municipalities, for overarching safety work (1)

\section{Discussion}

Although the manuals in our study, by and large, shared the same basic accident model, they also differed regarding other aspects. These aspects, and the consequences of the accident model used by the manuals, are discussed in section 8.1. The manuals had the same basic focus on few activities, but there was also considerable diversity. This is discussed in section 8.2. Moreover, the manuals had some coverage of safety work related to accident investigation, which we discuss in section 8.3.

\subsection{Accident models and scope}

Regarding scope, the manuals in this study did not include the social aspects of Heinrich's (1959) model, apart for the safety culture aspects of the Vägverket manual. They did, however include factors considered in Reason's (1997) more recent model, namely blunt end organizational factors, dangerous environmental conditions such as failed barriers, and aspects of people. They also described barriers as an important issue, the primary means of preventing accidents in Reason's model.

Some manuals included safety culture as a factor, which has been pointed out as a major contributing factor in accidents (e.g. Rollenhagen, 2005). Safety culture may also be seen as a performance condition, used in the functional resonance accident model. However, all manuals overlooked performance variability and resonance of functions as a cause, which was the main cause of accidents in the functional resonance accident model (Hollnagel, 2004). There was not much variation between the manuals regarding the kinds of aspects considered, but in addition to (hu)man, technology, organization, and safety culture, the aspect of anticipation was covered in one manual and economy of remedial actions were considered in another. These two aspects are at the core of the new resilience engineering approach to safe systems, being important stabilizing and destabilizing factors that affects movement of safe performance between different stable states. Thus, these factors, as well as functional resonance, might be well worth revisiting for future manuals, in the light of ongoing and future studies on resilience engineering and modeling of functional resonance.

In this study, the road safety (and workplace studies in general) domains most closely resembled the operators with unguarded machinery that was the focus of Heinrich's (1959) model. However, not even in these areas was the old model used. Road safety did have the aspects of social issues (that attempt to affect the social environment of 
Lundberg, J., et al. What-You-Look-For-Is-What-You-Find - The consequences of underlying accident models. Safety Sci. (2009), doi:10.1016/j.ssci.2009.01.004

children), and faults of people (people breaking rules) used in Heinrich's (1959) model. However, in addition, for situations were people had acted reasonably, errorprovoking conditions and barriers of Reason's (1997) model were included. The other manuals were quite similar with respect to issues considered, also following Reason's model, with active events and latent failures, considering organizational, human, and technical issues. Most manuals furthermore included information as a central aspect, something that Leveson (2004) has pointed at as central in many current complex systems. The Benner (1985) study unfortunately did not cover scope.

\subsection{Activities}

At large, the manuals had much in common when it comes to activities. They all focused mainly on analysis and representation (in particular on the report), with less focus on planning, creating the recommendations, and follow-up, and even less on implementation. Apart from the common aspects, most manuals had some unique aspects that other areas of investigation might benefit from considering also.

Checklists mainly supported data collection. Half of the manuals also described interactions with other parties, and some focused on preserving data.

Regarding representation and analysis, the manuals mainly used the Reason (1997) model, describing accidents as event sequences. Each event was seen as a sequence of factors, from the sharp end (in particular barriers), to the blunt end (in particular management). The main representational technique that the manuals focused on was the report. Most manuals provided a report template, and some provided instructions inside the template. Few manuals instructed on particular techniques for drawing or otherwise visualizing the event sequence although many such visualization techniques have been described in the literature (e.g. Johnson, 2003). In the Benner (1985) study, multi linear event sequences was given the highest ranking. No manual in this study instructed in the use of that method. However, in Benner's study, no methodology seems to have incorporated exactly the same methods as proposed in the manuals in this study. Also, in general, there seems to be much less variation in modeling schemes in this study compared to Benner's study. Unfortunately, the manuals in this study did not focus sufficiently on the same aspects as used in the study by Benner. Therefore a direct comparison using the same aspects was not possible.

The manuals were rather diverse when it came to the design of recommendations. They focused on different issues for creating alternative solutions, and different issues for evaluating them. The different areas could therefore learn a lot from each other regarding this step, especially since the literature is thin with regard to design of recommendations, as Johnson points out (2003) The overall lack of emphasis on design of recommendations implies that the manuals rely on the cause-analysis to create alternatives. The manuals thus implied that recommendations could be derived from the analysis, by eliminating the cause. However, the idea that one should provide "what" (the cause) to change, but not "how" is problematic, since what and how are relative - how on a specific level, becomes why if considered from one level below, and what if seen from one level above. Not all manuals emphasized the need for relating the specific recommendations to the damaged system as a whole. It is advisable to do so, since remedial actions have effects not only in casual chains, but also have effects in casual nets, radiating out from the changed place in the system. This is particularly important for systems where non-linear interactions would be expected, and where functionally independent processes may interact with each other due to sharing for instance the same components. In such systems, it is more dangerous to consider only linear relations, than in systems with linear, independent 
interactions. Although a cause-analysis can motivate the fix for a particular cause, based on one or several investigations, this does not overcome the problem that the fix may affect other activities or lead to unwanted side-effects. Regarding the manuals in this study hand, the complex linear models that were primarily used in these manuals focused on negative events in event sequences. It would therefore seem that the underlying accident model in these manuals works against relating parts to the whole. In contrast, for instance the functional resonance accident model places an emphasis on the whole, rather than on fragments that were involved in the accident. Therefore, an interesting question for future research is whether the tendency to focus on parts is tractable, when relying on event based models, and whether a systemic model would more naturally place a focus on the whole. In sum, what is found in the analysis is what will later be fixed, if these manuals are followed.

Regarding implementation of the recommendations, the manuals were also rather thin, but diverse, so again the manuals could learn from each other. A particular problem for implementation is that of specificity since, as mentioned, identifying a cause to fix is an act of design or of problem framing with many possible levels of specificity in describing what, how, or why. Moreover, handing the problem over brings problems of communication, to ensure that the recipient understands the problem to address. Further research is needed to evaluate these situations. In particular, it would be interesting to compare how people communicate in cases where the investigation is independent, directed towards an external organization, compared to situations where it is aimed at the own organization. On the one hand, a lack of independence could weaken the strength of recommendations. But on the other hand, improved communication of the problem to the recipient, could also improve the quality of implementation, and improve the understanding of the investigator of consequences of design decisions.

The follow-up step was not as diverse, with several manuals mentioning some kind of central analysis group. Most manuals mentioned some additional item, so the different areas of practice might learn from each other also regarding this step.

\subsection{System}

With regard to the system of investigation and its context of other safety related activities, the manuals were more differentiated, and have more to learn from each other. The manuals did not focus their descriptions on overarching safety work, but some important issues were nevertheless covered. A key issue for safety, which is closely related to the investigation itself, is dissemination of the report. It is a key issue in particular since the writing of the report was a central theme in the manuals. However, dissemination was not particularly well described in most manuals, and it was also divided into three foci. The manuals together described archiving, dissemination outside the organization, and internal dissemination. This is thus an area where the areas of practice could learn from each other.

Conducting event investigations is an activity embedded in a broader class of experience feedback activities such as collecting statistics about events, learning from external events outside the own organization etc. Some manuals focused on this issue, and suggested different kinds of groups that should deal with the bigger picture emerging from several reports. None of the manuals implemented the system groups advocated by Rollenhagen (2001).

Event investigation activities are also, or should be, strongly associated with risk analytical activities. For example, one could use findings from an event analysis 
Lundberg, J., et al. What-You-Look-For-Is-What-You-Find - The consequences of underlying accident models. Safety Sci. (2009), doi:10.1016/j.ssci.2009.01.004

(accident investigation) and simulate what could have had happened with slightly different circumstances. In most of the manuals studies, we did not find any elaborated discussions about how accident investigations relates to other safety management activities.

Benner (1985) noted that there was a lack of quality assurance with regard to the investigations and the investigations processes in his study. Although in our study, the matter was not covered in a systematic way in any manual, some manuals proposed steps in that direction, such as in the Banverket (Swedish Rail Administration) and Vägverket (Swedish Road Administration) manuals.

Future work is needed to investigate how accident manuals and the systems in which they are embedded are utilized in real practice. The formal/normative side of safety management systems does not necessarily conform to what takes place in practice. We are presently conducting research with the intention to investigate the practice of accident investigation and to compare practice with some of the beliefs reflected in accident manuals.

\subsection{Conclusions}

The manuals that were analysed all used complex linear models. The road safety domain in addition also used the much older domino model with regards to the factors considered. Interestingly, the domino model was to be used in cases where people distance themselves from the system, by for instance breaking rules, whereas the complex linear model was to be used for other cases, where people should be protected by the safety features of the road system. The factors considered were in general (hu)man, technology, organization, and information. Some manuals also include safety culture as a factor.

Because the manuals relied on complex linear models that focus on events and factors leading up to the events, there was a preoccupation with parts and a lack of focus on the whole. To focus on the whole it is necessary to use a more systemic model that goes from the whole to different factors involved in accidents (top-down), rather than the other way around (bottom-up). That approach might also make it easier to connect accident investigations with risk analysis, which is an issue that was lacking from the manuals. Taken together, the manuals provided some coverage of report dissemination and organizational learning, as well as quality assurance of the investigation process. However, the main emphasis was clearly on data collection, analysis, and report writing with only limited coverage of planning, design of recommendations, implementation, and follow-up. With regard to dissemination and organizational learning, it would be interesting to study how accident models are used in incident and accident statistics, in reporting systems, or in other parts of the overarching system of safety work. One example is the use of model specific categories such as 'latent failures,' 'violations,' etc.

\section{References}

Benner, L. (1985). Rating Accident Models and Investigation Methodologies. Journal of Safety Research, 16, 105-126.

Benner, L., Jr. (1975). Accident Investigations: Multilinear Events Sequencing Methods. Journal of Safety Research, 7(2).

Gordon, J. E. (1949). The Epidemiology of Accidents. American Journal of Public Health, 39(4), 504-515.

Heinrich, H. W. (1928). The Origin of Accidents. The Travelers standard, 16(6), 121- 
Lundberg, J., et al. What-You-Look-For-Is-What-You-Find - The consequences of underlying accident models. Safety Sci. (2009), doi:10.1016/j.ssci.2009.01.004

137.

Heinrich, H. W. (1931). Industrial accident prevention: a scientific approach (1 ed.). New York: McGraw-Hill.

Heinrich, H. W. (1959). Industrial accident prevention: a scientific approach (4 ed.). New York: McGraw-Hill.

Hollnagel, E. (2004). Barriers and accident prevention. Burlington, VT Ashgate.

Hollnagel, E. (2008). Investigation as an impediment to learning. In E. Hollnagel, C. Nemeth \& S. Dekker (Eds.), Remaining sensitive to the possibility of failure (Resilience engineering series). Aldershot, UK: Ashgate.

Hollnagel, E. (in print). The four cornerstones of resilience engineering. In C. Nemeth, E. Hollnagel \& S. Dekker (Eds.), Resilience Engineering Perspectives, Vol. 2, Preparation and restoration. Aldershot, UK: Ashgate.

Hollnagel, E., Woods, D. D., \& Leveson, N. (2006). Resilience engineering: concepts and precepts. Aldershot: Ashgate.

Johnson, C. W. (2003). Failure in Safety-Critical Systems: A Handbook of Accident and Incident Reporting. Glasgow, Scotland: University of Glasgow Press.

U. S. Department of Labor, Bureau of Labor Statistics. (1920). Standardization of Industrial Accident Statistics.

Leveson, N. (2004). A new accident model for engineering safer systems. Safety Science, 42, 237-270.

Perrow, C. (1999). Normal accidents: living with high-risk technologies. Princeton, NJ: Princeton University Press.

Reason, J. (1997). Managing the risks of organizational accidents. Burlington, VT: Ashgate.

Rollenhagen, C. (2005). Säkerhetskultur. Stockholm: RX media.

Rollenhagen, C., \& Kahlbom, U. (2001). Towards a method for the assessment of safety activities and their associated organisational context, The 4:th International Workshop on Human Error, Safety and System Development. Linköping, Sweden.

Sundström, G., \& Hollnagel, E. (2006). Learning how to create resilience in business systems. In E. Hollnagel, D. D. Woods \& N. Leveson (Eds.), Resilience engineering: concepts and precepts (pp. 253-271). Aldershot: Ashgate.

Turner, B., A. (1978). Man-Made disasters. London: Wykeham.

Van Schaardenburgh-Verhoeve, K. N. R., Corver, S. \& Groeneweg, J. (2007). Ongevalonderzoek buiten de grenzen van de organisatie (Accident investigation beyond the boundaries of organizational control). NVVK Jubileumscongres, 2526 April 2007, Sessie C, p. 1-11.

Woods, D. D., \& Cook, R. I. (2002). Nine Steps to Move Forward from Error. Cognition, Technology, and Work, 4, 137-144. 